\title{
An application of the option-pricing model to the valuation of a football player in the 'Serie A League'
}

\section{Daniela Coluccia, Stefano Fontana* and Silvia Solimene}

Department of Business and Law, University of Rome Sapienza,

Via del Castro Laurenziano 9, 00161 Rome, Italy

Email: daniela.coluccia@uniroma1.it

Email: stefano.fontana@uniroma1.it

Email: silvia.solimene@uniroma1.it

*Corresponding author

\begin{abstract}
Football is perhaps the most popular sport in the world. The market of football players is one of the most popular factors of the sport that makes the fans dream of each team which increases the interest around the sport. In 2013 the player Gareth Bale was sold from Tottenham to Real Madrid for 100 million Euros. Someone argues that the market for football players is inherently irrational precisely because of the sale price of certain players. This paper is based on Tunaru et al. model that is a real option based model. The aim of the paper is the financial valuation of a goalkeeper of Serie A League club. The model depends on relationship of player's and team's performance and the club's turnover.
\end{abstract}

Keywords: real options; valuation; football player; soccer; contingent claim analysis.

Reference to this paper should be made as follows: Coluccia, D., Fontana, S. and Solimene, S. (2018) 'An application of the option-pricing model to the valuation of a football player in the "Serie A League", Int. J. Sport Management and Marketing, Vol. 18, Nos. 1/2, pp.155-168.

Biographical notes: Daniela Coluccia is an Assistant Professor in the Department of Business and Law at the University of Rome Sapienza. She received his $\mathrm{PhD}$ in Accounting from the University of Roma Tre. Her major research interests are intellectual capital and voluntary disclosure.

Stefano Fontana is an Assistant Professor in the Department of Business and Law at the University of Rome Sapienza. He received his $\mathrm{PhD}$ in Accounting from the University of Roma Tre. His major research interests are business valuation, voluntary disclosure and corporate governance.

Silvia Solimene is an Assistant Professor in the Department of Business and Law at the University of Rome Sapienza. She received his $\mathrm{PhD}$ in Accounting from the University of Foggia. Her major research interests are financial accounting and financial performance analysis. 


\section{Introduction}

Soccer is one of the most popular sports in the world, especially in European and Latin America countries. The importance of economic transactions of football players among clubs led to the need to formalise the objectives and reliable systems for the evaluation of players, in order to align financial reporting practices to transparency and fairness and to sustainability and value of investments (by clubs and investors). Transfers involving top players with high market value never failed to hit the headlines. Market value varies greatly for different players, different areas and different periods.

Football clubs are engaged in three main activities. The first activity is generating revenues from ticket sales, broadcasting, food services and sponsorships. The second activity is trading (acquisition and disposal) of player contracts. The third activity is developing and nurturing in-house talent. The focus of this study is on the second activity. Still, football clubs may differ substantially in their intensity of reliance on trading players and on self-developed players.

The main justification for the transfer system, which governs player trading, is that clubs are entitled to recoup their investment in training and development of a player's skill. There are two types of player transfers between clubs: Transfers of players under contract and transfers of players outside contract (free agents). The main object of our study is to understand the way to define the amount of transaction paid by firms for soccer players.

The valuation of soccer players very rarely appeared in statistical studies for it is difficult to collect and organise data regarding this sport, even if Sports data in general has been a popular topic for statisticians in the recent years. People study various data in many different ball games and draw conclusions based on their analysis. Unlike basketball or American football, where the existence of a sole professional league makes it easy to record everything, soccer is played all around the world with so many leagues that it is difficult to consider about. Nowadays, the appearance of professional soccer statistics websites has made it possible to extent statistical study to the field of soccer. Although the availability of data has grown exponentially in the last 20 years, the process of valuing a player remains a combination of hard and soft data. Statistics are used alongside the insight of the manager and his coaching staff.

The main objective of this paper is the presentation of a case study on the evaluation of a football player's future perspectives in actual and future football clubs, through the stochastic calculus techniques, applying a relatively new theoretical model formalisation (2005), set up by Professor Radu Tunaru, Ephraim Clark and Howard Viney.

The model has been carried out to evaluate a major league Italian football player in order to test its applicability, but also to give evidence of the methodological difficulties that inevitably lead to some adjustments to adapt the technique to the case. Some favourable and some adverse considerations make users re-think on the way to apply this model. The choice to evaluate a player in the role of goalkeeper was not casual, as we wanted to focus attention on a role that is not easily replaceable as he is generally unique in his role (his reservations do not very often play during a match, unless he belongs to prestigious clubs where the turn over plays an important role for the large number of matches that these clubs face during the season).

The contribution of our case study is to apply for the first time such a methodology to the Italian context, in order to highlight its reliability and the adoptability of the method, as far as possible, to highlight the positive and negative aspects of the methodology itself. 
The paper is structured as follows.

Section 2 is devoted to general accounting rules for football players in soccer clubs and the limits of the accounting procedures within IAS 38 rules.

In the third paragraph, it is shown the economic evaluation of a football player using the option pricing method. The fourth section is on the application of the selected method, using the Tunaru et al. (2005) approach. In Section 5, it is presented the estimation of all the financial and non-financial variables that lead to the valuation of an 'Alfa' football player.

In the last section we will make some conclusions on this work.

\section{Accounting and valuation for the value of football players}

Even though our focus is on the evaluation of football players in transactions, so to define the economic value of these peculiar assets within the equity of a firm, it seems proper to summarise some accounting principles in the recognition of players within financial statement.

In accounting terms, the football clubs may adopt local or international accounting standards to players' performance; in both cases, the performance of players are accounted for as long-term rights to benefits and, as such, must be regarded as contracts, i.e., intangible assets (Forker, 2005).

IAS 38 requires that an asset to be recognised has to be non-monetary, identifiable, without physical substance, held to produce goods or services, for renting third parties or for administrative purposes; that is, it is necessary that assets comply with the criteria of identifiability, controllability and the attitude to produce future economic cash flows to firm. The rights to control football performance are transferable autonomously compared to the rest of the equity, they benefit from a strong legislative protection, so that the club is only able to perceive the future economic benefits arising from the activity and image of players. Finally, it is clear that these assets produce an inflow of economic benefits.

As mentioned before, the disclosure of players within the financial statements is potentially problematic because there is no solid ground for valuation and no active market for comparable parameters (in order to supply a credible value). For football players, the accounting process is hard to complete because human resources are not unique in their specific characteristics, nor they can be recognise in financial statements because they are human resources. However, without players, football clubs would not exist, so that they are the most important asset to them (Lozano and Gallego, 2011).

To this, there are some accounting and valuation methods developed by theorists within human resource accounting field that can be applied to the valuation of football contracts on players' performance, in consideration that the right to use a player performance is ensured by the contract that can be accounted as an intangible asset. The transfer prices at the date of the contract signature by a player represent the value of the player at the same time. To determine the transfer-price of a football player between clubs there are different approaches.

The first approach in based on the capitalisation of the compensation of a soccer player (Gröjer and Johanson, 1991). In this way, it is possible to have an estimative value of the player's contract connected to the initial investment by the firms. In order to capitalise the compensation, you need to know the duration of the contract and the 
wage/salary firms pay to their soccer players. The method was corrected over time (in the $90 \mathrm{~s}$ ), in order to incorporate in a multiplier of the salary of players other variables devoted to update the value of players over their economic life.

This type of valuation is adequate for free agents, who are players under Bosman ruling (Antonioni and Cubbin, 2000; Feess and Muehlheusser, 2003), where the negotiated wage would be considered appropriate as valuation ground (Opreana and Oprisora, 2014). The major limit of this theory is that firms have to control/have the property of the soccer players, intended as intangible asset. The definition of 'asset' lies in the fact that firm does expect cash inflows from its utilisations and that it can control these activities. Actually, the relation between arm's length investment in player contracts by football companies and future benefits is to be very tenuous. Further, the short duration of these contracts may cast doubt on the applicability of the capitalisation rules. It is unknown the way a player will produce cash flows in future and control over the human resource is relative. Further, this method does not take into account the profitability of investors or the risk remuneration, as well as the updating of players' salary over the contract (Scarpello and Theeke, 1989). In conclusion, these accounting approaches raise many limits to be applicable to the valuation of players in football. Amir and Levine (2005) also empirically tested this lack of linking between capitalisation and football player value. In their conclusion, the relatively weak results of the association between transfer fees and future benefits accompany the results of market-based tests, which show a strong correlation to market value of a firm equity.

In addition, other approaches show their weakness. For instance, the one based on market transactions, in not applicable because of the absence of an active market for a unique soccer player. In the transfer context is to be also considered the bargaining power of parties (team clubs).

In conclusion, after the initial recognition, it is necessary be very careful to the value in use of rights to use players' performance, not only for occasionally impairment losses under IAS 36, but above all for transfers among clubs during the buy-sell season. The revaluation option, after initial recognition, generates many problems. Due to lack of revaluation options, to us it is clear than accounting procedures of player registrations does not reflect the true and fair financial status of the club, since the market value of players under contract is likely to significantly exceed the book value of the registered players. For this reason, major parts of clubs favour the historical cost and straight-line depreciation model. When a player is sold, it is generated a huge amount of gains that do not justify the realisation of a goodwill. The revaluation model would be suitable in order to diminish potential hidden values and present a truer and fair view of the intangible assets. As clubs only capitalise the value of the contract at each specific period, the real value (market value) of the player is not taken into consideration (Bengtsson and Wallström, 2014).

In order to present a more fair value of the players, a revaluation model would need to be created because of the distance between fair value and book value of rights. Further, such a model would most likely lead to higher volatility of the clubs equity. Another problem with creating a revaluation model would be to decide the market price for the player, due to the fact such a value underlines many aspects: such as: reputation of player, their past performance, their age and the relevance of club that buys or sells compared to competitors. 
In order to find a way to state the real and fair value of a soccer player, in literature (Likert, 1967; Flamholtz, 1972, 1999; Flamholtz et al., 2002) it has been shown that the price-transfer of an employee, in this case of a football player, is affected by quantitative (wage, duration of contract, etc.) and qualitative data (principally behavioural and organisational in a probabilistic approach). The interaction between the individual and organisational determinants mentioned above, leads to job satisfaction. The higher is the level of job satisfaction; the lower is the probability of employee turnover. Therefore, higher is the expected realisable value.

Mixed approaches also consider, for instance, recruitment costs to an employee's contract. In this specific case, recruitment costs, in which there are embedded firms' past investments, better explains the value of a football player than an estimation method based on the capitalisation of the future wage payments (Opreana and Oprisora, 2014). The value of a soccer player, in fact, has an unpredictable evolution over the career, due to many factors that clubs cannot forecast, first the chance to a player to negotiate freely with other clubs even when the value of contract at the end of it is equal to zero. Therefore, a mix of factors variously combined influence the price transfer of a football player. Taken alone, these factors do not reflect the amount paid by a firm to have a player in their team. Systemically, they work out to explain the record level given to some transfers, even if football teams are in bad financial situations.

Since multi-yearly right to the performance of professional players can be classified as an intangible asset, the methods of revaluation that are theoretically applicable are those currently used to estimate in practice such assets.

The methods used by the practice for the economic valuation of the fair value of intangible assets are mainly referred to the purchase or replacement costs of players, or to the discounting of the future cash flows expected from the company, or finally to the transactions comparable market.

These methods have problems that do not reflect current market values for several reasons. For example, the cost-based method (Rowbottom, 2002) is irrationally applied to the fact that a player can not be replaced. In addition, the method based on the discounting future economic benefits from the use of the player (Amir and Levne, 2005) does not allow to find a relationship between the performance of individual players and cash flows to the team. The latter are influenced by the performance of the whole team, as well as by other external factors (the fame of the brand, the number of fans, etc.) but are not related to the quality and the economic value of individual rights .

The most commonly used method of comparable transactions consists of price analysis in transactions of comparable goods and rights and in the statistical regularity between negotiated prices and the characteristics of goods or rights. However, its credibility varies depending on the spread of market transactions and the statistical convergence of negotiated prices. For the type of rights to be evaluated, the only references are similar transactions on the market and some public statistics. Market transactions are not comparable because of the object of transaction (specific players). Further, the final price it is largely dependent on the contractual ability of the involved parties.

In the next section, we will give some explanation of an alternative valuation model for football players, based on the contingent claim analysis. 


\section{Valuation of football players from an option-pricing perspective}

Besides the above-mentioned considerations, we turn our attention to the financial valuation in transfers in order to apply the Tunaru et al. (2005) option-pricing model for valuation of football players.

We will actually disregard all cost-based, all capitalisations of future inflows methods and linear modelling techniques, to focus to a specific innovative methodology, which is based on statistical evaluations using stochastic calculations, referring to the study by Black and Scholes (1973) in assessing the price of real option.

The opportunity to model a football player value by Brownian motion with a Poisson's law jump takes inspiration form the observation of Fama (1963) who noticed that distribution of the financial returns of an asset is not normal but leptokurtic [used in the financial model by Black and Scholes (1973)].

In an uncertain environment, with uncertain cash flow and specific risks, it could be useful to evaluate a soccer player by using a portfolio of options on him (intended as a real asset), combined with interdependent future scenarios and perspective, in a stochastic approach. So that, the valuation of a football player depends on his contribute to the team's revenue, on past injuries, on his career's perspectives, on his probability to improve his performance.

In this section, we will consider the evaluation methodology of the rights of players based on 'contingent claims methodology' and techniques of statistical modelling standards and stochastic calculus. Through such a method, it is possible to reach the financial value of the professional player from an internal point of view (football club for its own needs) and from an external point of view of a third club that might be interested in purchasing the player. To this purpose, it is necessary to perform two different calculations to identify the value a player assumes to the club that 'owns the rights' as the value to other clubs, because of a certain level of correlation between the performance of players and the team they play.

The method involves various factors that influence the final value, among these the performance on the ground, injuries and conduct, as well as others that might seem less severe, such as image rights or the players' personal condition (Kanyinda et al., 2012).

In order to determine the financial value of the player, the model uses a score that can indicate the performance past trend of the player and the team he belongs to. The scale of scores is that one offered by the British company opta sports. The company is responsible for recording the performance of all the teams and players on the major European markets (Premier League, Ligue1, Bundesliga, 'Serie A' and UEFA Champions League) operating in multiple sports, including football, giving them a score, in fact, called opta index. As mentioned before, the contingent claims model is used differently both for the evaluation of players and for corrections to the assessment due to swings in the value (caused by injuries).

The originality of this method is that it considers different factors, while evaluating a soccer player. In addition to providing a financial value to him, its statistical characteristics help to investigate the relationship between different aspects. It can link the performance of a player (or pair of players) to the team membership, to the trend in the performance of a player or a team registered in a given period or, finally, to the relative value of players with similar features but with different market valuations. 
Among the main aspects of this model, there is a substantial excess of the techniques based on market values. The latter seek to find homogeneity between players, but such homogeneity does not exist as each player represents a set of unique qualities in different combinations that are unlikely to be kept into rigid evaluation classes. Further, market models assume the presence of a real market, without even debated among scholars, who wonder if few months a year are sufficient to define a market as 'active'. On the contrary, the former is based on performance data to define the value of a player and attempts to locate the most likely path of future evolution of the player by stochastic calculus paths.

\section{The application of the Tunaru et al. (2005) model to a 'Serie A League' player}

In this section we will apply the Tunaru et al. (2005 - 'the Authors') pricing model to a single case within Italian football major league player. Then we will adapt their model to Italian context, when needed. In particular, we selected a player not due to his excellences nor his prestige, but only for him to belong to the higher ranking among the Italian Premier League clubs, listed on the Milan Stock Exchange, for the season 2009/2010, so to have the availability of all the requested data.

Occasionally, we will refer to the authors just to make comparisons between our case study and that one performed by the authors, in particular to justify any adaptation from the original methodology.

Figure 1 Opta index for Beta FC over the season 2011-2012 (see online version for colours)

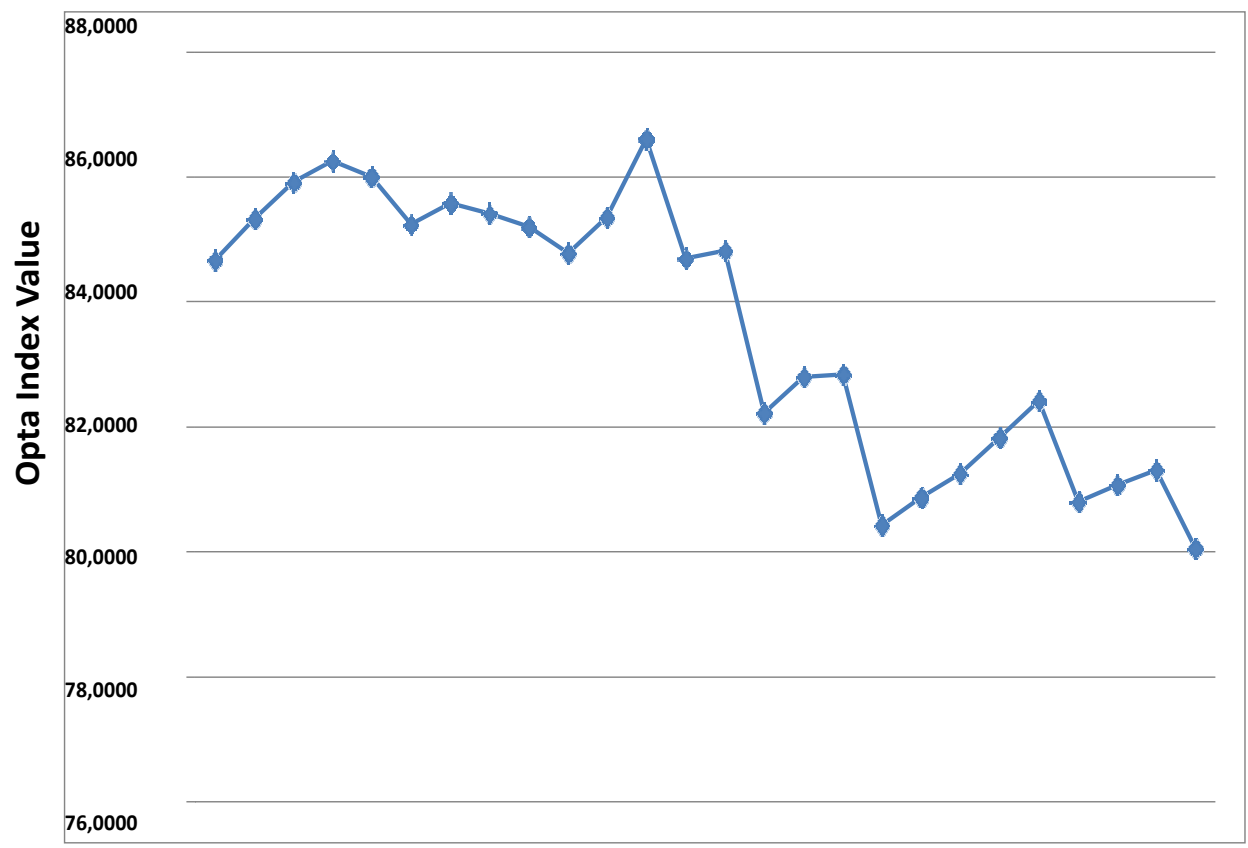


We selected a five-year contract player with his club (starting on July 52010 and expiring on 30 June 2015) and one of the most participating players among the Italian League in the period. The acquisition of the player (a goalkeeper) took place as a purchase for 5,049,363.46 Euros from another team. The net book value at 30 June 2010 is 4,048,913.29 Euros, without suffering write-downs. His annual wage is 1.1 million Euros. The revenues of the football club are 69,498,000 Euros.

We'll call generically the football player 'Alfa' and the football team 'Beta FC'.

The paper of Tunaru et al. (2005) uses 'opta index points' as a proxy of how good a player is. In the following tables are showed the opta indices for Beta F.C. and Alfa player over the season 2011-2012. Opta index war born in 1996 and it is the leading provider of sports performance data.

Figure 2 Opta index for Alfa player, over the season 2011-2012 (see online version for colours)

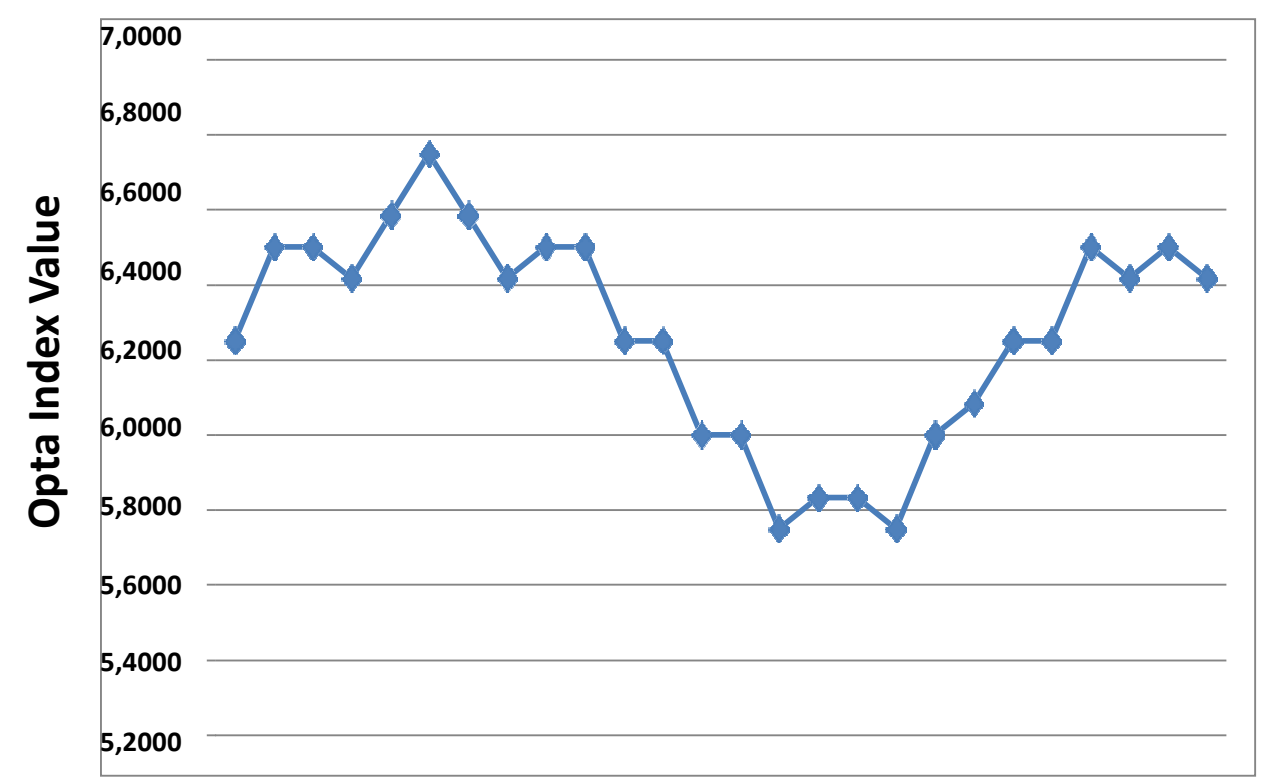

The opta index is a statistical database that tracks all goals, passes, mistakes, etc., a player does every match and therefore it is a good proxy for performance. We use the same notations as in Tunaru et al. (2005) paper, so $T$ are revenues of the football team and $N$ the number of opta index points for the individual player under evaluation and $S$ be the sum of opta index points for all players playing for the club.

The Tunaru et al. (2005) model imposes that the financial value per opta index point for the club is

$$
X=\frac{T}{S}
$$

and the opta value of the player is:

$$
Y=N X
$$


Tunaru et al. (2005) assume the revenue $(T)$ and the opta value $(S)$, that is a measure of the performance of the whole team, follow a correlated geometrics Brownian motions according the following differential equations:

$$
\begin{aligned}
& d T=\alpha T d t+\sigma T d z \\
& d S=\gamma S d t+\delta S d w
\end{aligned}
$$

where $\alpha$ and $\gamma$ are the drift rates and $\sigma T d z, \delta S d w$ are the terms that represent the uncertainty, where $d z$ and $d w$ are Wiener process. The correlation between the two processes is

$$
E(d z d w)=\rho d t
$$

The basic idea is that $(T)$ and $(S)$ are mutually conditioning, so an increase of $(S)$ is a good proxy of the performance and if performance improves, this affects revenue $(T)$. So the equation (3) captures the expected development and uncertainties concerning the football club's revenues while the equation (4) captures the expected development and uncertainties concerning the football club's performance.

Moreover the number of opta index points for an individual player is also assumed to follow a geometric Brownian motions, the trend of the future performance of a player is represented by the differential equation:

$$
d N=a N d t+b N d h
$$

Tunaru et al. (2005) consider a football club as a portfolio which it is composed by football players. The skills of each individual player are represented by opta index points. For all the players in the portfolio, $S$ is the sum of each player's $N$. In a financial perspective $S$ is considered as a stock index. The opta index gives us the information about the players today, but there is no possibility to know the future performance of the player. The equation (6) provides to estimate the future development of $N$ according to the Brownian motion, where $(a)$ is the drift rate and $(b)$ is the volatility and $d h$ is the Wiener process. In the model we expect that the value of drift, for a player early in his career, will be greater than zero, that tends to zero during the period of peak performance, which for a player (on the average) coincides with an age between 26 and the 31 years. After 31 years, this number tends to become negative.

The model to evaluate a player according to Tunaru et al. (2005) is:

$$
\mathbf{V}=\left\{\left[\frac{\partial \mathrm{V}}{\partial \mathrm{t}}+D Y \frac{\partial \mathrm{V}}{\partial \mathrm{Y}}+\frac{1}{2} \mathbf{B}^{2} \mathbf{Y}^{2} \frac{\partial^{2} \mathrm{~V}}{\partial \mathrm{Y}^{2}}+\lambda G(\mathbf{V})\right] d t\right\} \frac{1}{\mathrm{r}}
$$

where:

$\partial \mathrm{V} / \partial \mathrm{t}$ is the partial derivative that represent the change in value $(V)$ over time $(t)$

$\partial \mathrm{V} / \partial \mathrm{Y}$ is the partial derivative that represent how much the player's financial value $(V)$ change when the opta value $(Y)$ change.

$$
B=\sqrt{b^{2}+\sigma^{2}+\delta^{2}-2 \sigma \delta \rho}
$$

where all symbols are known 


$$
D=\alpha+\delta^{2}-\gamma-\delta \rho \sigma+a+\psi \sqrt{\sigma^{2}+\delta^{2}-2 \sigma \delta \rho}
$$

where all symbols are known and

$\psi \quad$ is the correlation between the $N$ and $X$

$\partial^{2} \mathrm{~V} / \partial \mathrm{Y}^{2}$ is the partial second derivative that represent if the effect of increased opta value $(Y)$ on value $(V)$ is accelerating or diminishing

$\lambda G(V) \quad$ is the function that measures the potential loss in case of injuries, the loss will be the maximum and occurs if a player is injured all the time when $\lambda$ is equal to one

$r \quad$ is the interest rate.

\section{The valuation of goalkeeper 'Alfa'}

As said previously we have chosen to evaluate the goalkeeper Alfa of the Beta FC, an Italian football club of 'Serie A League'. He was 28 years old at starting of season 2011-2012.

He also was in the same period the second goalkeeper of Italian national football team. The mean revenues of the club in the previous three years are 69,498,000.00 Euros. The value according opta for the whole team $(S)$ is 83.6071 and value $(N)$ for Alfa goalkeeper is 6.2724. The values are summarised in Table 1.

Table 1 Values for developing the model

\begin{tabular}{lcc}
\hline Beta's revenue (Euro) & $\mathrm{T}$ & $69,498,000.00$ \\
Value of team Beta FC & $\mathrm{S}$ & 83.6071 \\
Value of Alfa player & $\mathrm{N}$ & 6.2724 \\
$\mathrm{~T} / \mathrm{S}$ & $\mathrm{X}$ & $831,245.19$ \\
$\mathrm{~N}^{*} \mathrm{X}$ (Euro) & $\mathrm{Y}$ & $5,213,902.35$ \\
\hline
\end{tabular}

\subsection{The estimate of the correlations drifts and volatilities}

We have calculated the correlations drifts and volatilities of the items present in Section 4 . The data are presented in Table 2.

Table 2 Correlations drifts and volatilities

\begin{tabular}{llc}
\hline Correlation T and S & $\rho$ & 0.7400 \\
Correlation N and S & $\psi$ & 0.3360 \\
Expected growth rate of revenues & $\alpha$ & 0.0500 \\
Drift rate in team performance & $\gamma$ & -0.0469 \\
Individual drift rate & $a$ & 0.1404 \\
Volatility of revenues & $\sigma$ & 0.3000 \\
Volatility of team performance & $\delta$ & 0.0775 \\
Individual volatility & $b$ & 0.1482 \\
\hline
\end{tabular}

In the model we have observed that the correlation $(\rho)$ between the revenues of the club and team's performance is 0.74 , this involves that around of $26 \%$ of revenues does not 
depend by team's performance. The correlation $(\psi)$ is very low, 0.33 because the team has a broad roster with lower performance than other clubs with super top players such as Barcellona, Real Madrid, Bayern, etc. In fact, the performances of Beta FC are based on samples of medium quality players but not top players. In fact the expected drift rate in team performance $(\gamma)$ and the volatility of team performance $(\delta)$ are both very low. We see a medium expected growth rates of revenues $(\alpha)$ and a high level in volatility $(\sigma)$ that confirms that revenues are related to other factors and not just the performance (Tunaru and Viney, 2010). Finally the expected drift rate of individual performance $(a)$ and the volatility in individual performance $(b)$ are respectively 0.1404 and 0.1482 .

\subsection{The financial value of injuries}

The function that measures the potential loss in case of injuries is $G(V), \lambda$ the intensity parameter for injuries. For ease of calculation it was decided to set the maximum loss function as $(-Y)$. In the considered season the player Alfa was injured for 4.5 weeks. The value of $\lambda$ is calculated as number of weeks of absence divided by number of weeks (52) in one year. The values are summarised in Table 3.

Table 3 Variables in the the financial value of injuries

\begin{tabular}{lcc}
\hline Maximum loss in monetary terms (Euro) & $-Y$ & $5,213,902.35$ \\
Number of weeks of absence & $K$ & 4.5 \\
Number of weeks in one year & $W$ & 52 \\
Intensity parameter for injuries $=\mathrm{K} / \mathrm{W}$ & $\lambda$ & 0.087 \\
The expected maximum loss (Euro) $=\lambda *(-\mathrm{Y})$ & $\lambda G(V)$ & $-451,203.088$ \\
\hline
\end{tabular}

\subsection{The financial value of the player}

After calculating the parameters in the previous tables, we can applied them to the equation (7) as shown as follows.

Table 4 Variables in the model to determine the financial value of the football player

\begin{tabular}{lcc}
\hline Inputs & Symbol & Value \\
\hline $\begin{array}{l}\text { Partial derivative that represent the change in value (V) over time } \\
\text { (t) }\end{array}$ & $\partial V / \partial t$ & $500,000.00$ \\
Alfa's performance value & $Y$ & $5,213,209.35$ \\
$D=\alpha+\delta^{2}-\gamma-\delta \rho \sigma+a+\psi \sqrt{\sigma^{2}+\delta^{2}-2 \sigma \delta \rho}$ & $D$ & 0.2387 \\
$B=\sqrt{b^{2}+\sigma^{2}+\delta^{2}-2 \sigma \delta \rho}$ & $B^{2}$ & 0.0841 \\
Partial derivative that represent how much the player's financial & $\partial V / \partial Y$ & 0.15 \\
value (V) change when the Opta value (Y) change & $\partial^{2} V / Y^{2}$ & $8 * 10^{-8}$ \\
Partial second derivative that represent if the effect of increased & & \\
Opta value (Y) on value (V) is accelerating or diminishing & $\lambda G(V)$ & $-451,203.09$ \\
The expected maximum loss (Euro) & $r$ & 0.0323 \\
Interst rate & \multicolumn{2}{c}{$10,050,000.00$} \\
\hline Output & $V$ \\
\hline Financial value of Alfa player (Euro) &
\end{tabular}


Let make some considerations about the formula (7). The $\partial^{2} \mathrm{~V} / \partial \mathrm{Y}^{2}$ must be a low value because, if not, it could result in an overestimation. Since the duration of the contract of the goalkeeper is five years it was deemed right to adopt, as the interest rate, the gross rate of return of five years Italian Government Bond. The financial value of the goalkeeper is 10,050,000 Euros.

\section{Conclusions}

The value of a player is very difficult to quantify, some authors (Swanepoel, 2016) argues that the market for football players are inherently irrational where "value is what fools are willing to pay for it', implying the existence of a winner's curse in the football transfer market. Among other things, they assume that there is a real market, the fact still debated among scholars, who wonder if the three months a year of negotiations are sufficient to define a market as 'active'. Tunaru et al. (2005) study is based on real options models and it is based on performance data to define the value of a player. The objectivity and comprehensiveness of this data must be completed or at least standardised. Through these data, we try to identify the most likely path of future development of the player by means of stochastic calculus courses.

Among the main positive aspects of the model there is a substantial overcoming techniques based on market values. The latter try to find consistency between the players, but such uniformity does not exist because every player is a set of qualities in different combinations and concentrations that are unlikely to lend to the inclusion of strict evaluation classes. The main problem of the model, however, in not providing reliable valuation solutions for players who play little or spend the entire season on the bench. So the model described by the authors would be applicable for players present in the field for most of the season.

Our contribution is to validate a model that in the Italian context has never been applied before in practice for the estimation of the economic value of rights on a footballer. So far, the price of players' rights in transactions depends on contract parties' strength (football teams), regardless of the object of transaction (human resource). Our attempt is to provide an objective representation of the value of footballers' rights, focusing on the fact that the transaction underlies human resources that otherwise it is forbidden to sell. We also tried to put the attention on the player and its characteristics and not on the negotiating power of the parties involves in the transaction.

Further, we do not want to propose a framework to account for the rights on a footballer, we stay in the field of economic valuation. However, the application of the option pricing model can also be useful to avoid overestimation of the players' value. In Italy, there has been a rise of the cost of players in the financial reports of leading clubs since the 2000s due to the purchase, remuneration and amortisation of linked multi-year costs (Risaliti and Verona, 2012). The losses of soccer teams can not be sustained in the light of the millions of Euros spent for a single player.

An objective evaluation of footballers therefore becomes necessary, with particular reference to the Italian context. This value is functional not only to fix the actual selling price but also to account for the fair value, as a revaluation option model, since the listed companies adopt IAS 38 to intangible assets. According to the standard, the fair value is to be intended as the sum of money that, under market conditions at the time of valuation, a generic rational and properly informed economic operator would be willing to pay for 
the acquisition of the right, according to the legal arrangements provided by the current law on sporting rights. The same goes for the unlisted companies for the estimation of the recoverable amount from the rights, in accordance with the combined provision of art. 2426 Civil Code and Art, 18bis of Law 91/81, as amended by the Law of Conversion of Decree Law 282/2002.

At present, the price estimated on a player does not reflect the player's ability and conditions, but only the power that the teams exert. The present application of the Tunaru et al. (2005) model, on the other hand, may be useful in providing an objective fair value measurement to be included in the expertise, at least as a comfort assessment method. From an accounting point of view, this application may help to define an accounting measure for a reasonable and sustainable value of players.

The assessment that this model proposes cannot deviate from the enhancement of human resources accounting practices from a prospective point of view. In this way, the economic evaluation of rights linked to a player, which differs from the actual transaction price, should represent, as much as possible, the fair value, reflecting the physical condition of the player and his future contribution to the team and taking into consideration the stage of his career, age and probability of injury.

Given the difficulty of identifying an objective way for player assessment, accounting and valuation, this empirical approach through the option pricing model may offer an alternative methodology available to the evaluator, although it is not easy to apply due to several system factors to be considered in the algorithm.

The simulation we propose in this paper aims to overcome the great difficulties to the definition of the fair value of player rights, both with regard to the valuations after the initial recognition, in the case of the use of international accounting standards, both with reference to economic evaluations in the case of a transaction (Morrow, 2013).

The option pricing model, considering many variables, including the probability of injury in the valuation process, makes a correction in this particular industry where transactions are affected by discretional factors and alter the conditions and the functioning of market. It could also be used as an alternative evaluation method to avoid artificial overcompensation (Risaliti and Verona, 2012).

Finally, the unique empirical application of this model made by Tunaru et al. (2005) is on Thierry Henry, a top player in Europe. Our analysis, on the other hand, is carried out on a player who is not a top player and who is a goalkeeper. This implies that this role has few terms of comparison as to other players (as defender, midfielders and strikers). It is not easily comparable. After our analysis, we can conclude that this model could be applied to every role. We can make such a conclusion also considering that the value we estimated is in line with the value that at the time of evaluation was reported by some date football providers.

\section{References}

Amir, E. and Livne, G. (2005) 'Accounting, valuation and duration of football player contracts', Journal of Business Finance \& Accounting, Vol. 32, Nos. 3/4, pp.549-586.

Antonioni, P. and Cubbin, J. (2000) 'The Bosman ruling and the emergence of a single market in soccer talent', European Journal of Law and Economics, Vol. 9, No. 2, pp.157-73.

Bengtsson, M. and Wallström, J. (2014) Accounting and Disclosure of Football Player Registrations: do they Present a True and Fair View of the Financial Statements?, Working Paper of Jönköping International Business School, Jönköping University. 
Black, F. and Scholes, M. (1973) 'The pricing of options and corporate liabilities', Journal of Political Economy, Vol. 81, No. 3, pp.637-654.

Fama, E. (1963) 'Mandelbrot and stable Paretian hypothesis', Journal of Business, Vol. 36, No. 4, pp.420-429.

Feess, E. and Muehlheusser, G. (2003) 'The impact of transfer fees on professional sports: an analysis of the new transfer system for European football', Scandinavian Journal of Economics, Vol. 105, No. 1, pp.139-154.

Flamholtz, E. (1999) Human Resource Accounting. Advances in Concepts, Methods and Applications, 3rd ed., Kluwer Academic Publishers, Norwell, Massachusetts.

Flamholtz, E.G, Bullen, M. and Hua, W. (2002) 'Human resource accounting: a historical perspective and future implications', Management Decision, Vol. 40, No. 10, pp.947-954.

Flamholtz, E.G. (1972) 'Toward a theory of human value in formal organizations', The Accounting Review, Vol. 47, No. 4, pp.666-678.

Forker, J. (2005) 'Discussion of accounting, valuation and duration of football player contracts', Journal of Business Finance \& Accounting, Vol. 32, No. 3/4, pp.587-598.

Gröjer, J.E. and Johanson, U. (1991) Human Costing Resource and Accounting, Arbetarskyddsnamndem, Stockholm.

Kanyinda, A., Bouteiller, C. and Karyotis, C. (2012) 'Human capital: assessing the financial value of football players on the basis of real options theory', Investment Management and Financial Innovations, Vol. 9, No. 4, pp.27-37.

Likert, R.M. (1967) The Human Organization: Its Management and Value, McGraw Hill, New York.

Lozano, F.J.M. and Gallego, A.C. (2011) 'Deficits of accounting in the valuation of rights to exploit the performance of professional players in football clubs. A case study', Journal of Management Control, Vol. 22, No. 3, pp.335-357.

Morrow, S. (2013) 'Football club financial reporting: time for a new model?', Sport, Business and Management: An International Journal, Vol. 3, No. 4, pp.297-311.

Opreana, V.B. and Oprisora, T. (2014) 'Accounting for soccer players: capitalization paradigm vs. expenditure', Procedia Economics and Finance, Vol. 15, pp.1647-1654.

Scarpello, B. and Theeke, H.A. (1989) 'Human resource accounting: a measured critique', Journal of Accounting Literature, Vol. 8, pp.265-280.

Risaliti, G. and Verona, R. (2012) 'Players' registration rights in the financial statements of the leading Italian clubs', Accounting, Auditing \& Accountability Journal, Vol. 26, No. 1, pp.16-47.

Rowbottom, N. (2002) 'The application of intangible asset accounting and discretionary policy choices in the UK football industry', The British Accounting Review, Vol. 34, No. 4, pp.335-355.

Swanepoel, M.J. (2016) 'The correlation between player valuation and the bargain position of clubs in the English premier league (EPL)', International Journal of Economics and Finance Studies, Vol. 8, No. 1, pp.209-225.

Tunaru, R. and Viney, H. (2010) 'Valuations of soccer players from statistical performance data', Journal of Quantitative Analysis in Sports, Vol. 6, No. 2, Article 10.

Tunaru, R., Clarke, E. and Viney, H. (2005) 'An option pricing framework for valuation of football players', Review of Financial Economics, Vol. 14, Nos. 3-4, pp.281-295. 